\title{
OCTAGON SHAPED MICROSTRIP PATCH ANTENNA FOR DUAL BAND APPLICATIONS
}

\author{
S.Mridula, Binu Paul, C.K.Aanandan and P.Mohanan* \\ Department of Electronics, \\ Cochin University of Science and Technology \\ Cochin 682 022, India \\ Email :mohan@doe.cusat.edu ,drmohan@cusat.ac.in
}

\begin{abstract}
:
The paper proposes an octagon shaped Microstrip Patch Antenna suitable for dual band applications. The striking features of this compact, planar antenna are sufficient isolation between the two operating bands and an area reduction of $29 \%$ in comparison to a conventional circular patch antenna operating in the same band.
\end{abstract}

\section{INTRODUCTION}

Recent breakthroughs in wireless communication technology focus on a single low cost mobile terminal equipped to operate in different regions of the world, in different frequency bands. Therefore, there is an immediate need for a single, multi band - multi function handset allowing users to switch freely between existing cellular networks. Dual frequency behavior can be obtained through several techniques, such as multilayer substrates, addition of parasitic elements, loading the patch with reactive elements, etc. [1]. Basically, microstrip patches require two elements of different dimensions, resonating in the required frequency bands to achieve dual band characteristics. The potential of an irregular shaped planar antenna has been proposed for multi - band operation [2]. Perturbation of the shape of a conventional microstrip patch antenna in a prescribed manner also results in multi - band operation [3]. But, most of these techniques achieve dual frequency operation by either increasing the patch size or using complicated manufacturing methods.

This paper focuses on a compact octagonal microstrip antenna designed to operate at $1.8 \mathrm{GHz}$ and $2.4 \mathrm{GHz}$. The frequencies chosen for the study are those allotted for Mobile Communications and Blue tooth applications respectively. Bluetooth is a relatively new comer in the field of RF technologies for wireless communication. Bluetooth operates in the $2.4 \mathrm{GHz}$ ISM (Industrial Scientific Medical) frequency band [4]. The frequency presently allotted for Mobile communication applications is $1.8 \mathrm{GHz}$. Microstrip antenna is an ideal choice for these applications by virtue of its conformal and planar structure. 


\section{DESIGN AND METHODOLOGY}

Figure.1. shows the geometry of the octagonal patch antenna of dimensions L1x $\mathrm{L} 2 \times \mathrm{L} 3$. The dimensions of the antenna designed to operate at $1.8 \mathrm{GHz}$ and $2.4 \mathrm{GHz}$ is $24 \mathrm{~mm} \times 15.5 \mathrm{~mm} \times 10 \mathrm{~mm}$. The antenna is fabricated on a substrate of dielectric constant $\mathrm{Er}=4.28$ and thickness $\mathrm{h}=1.6 \mathrm{~mm}$. The two ports are energized electromagnetically using two $50 \Omega$ orthogonal microstrip lines. The feed lines are also fabricated on a similar substrate. The feed locations are optimized at $F 1=12 \mathrm{~mm}$ and $F 2=3.5 \mathrm{~mm}$ from the geometric centre of the patch.

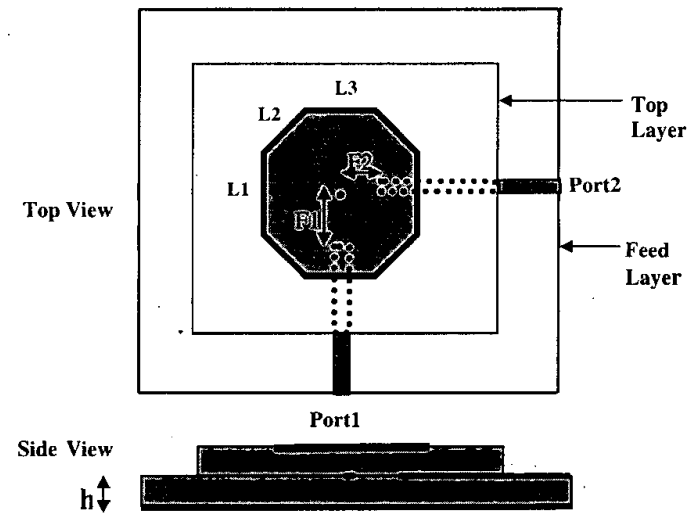

Figure1. The proposed antenna geometry

The antenna presented here is designed and analyzed through EM simulation. The commercial simulator IE3D from Zeland Software, based on the method of moments, has been used. A resolution of 20 cells per wavelength has been used in simulations. The reflection coefficient and radiation pattern measurements have been carried out by means of an HP $8510 \mathrm{C}$ network analyzer.

\section{SIMULATED AND EXPERIMENTAL RESULTS}

Simulated and measured input return loss are shown in Figure.2. It is noted that the experimental results are in good agreement with the simulated results. Port 1 operates in the band $1.7625-1.8313 \mathrm{GHz}$ and Port 2 operates in the band $2.3625-2.475 \mathrm{GHz}$. The 2:1 VSWR impedance bandwidths obtained are $3.82 \%$ and $4.65 \%$ respectively for ports 1 and 2 . The antenna offers linear polarization for the two ports and the polarizations are orthogonal to each other. The isolation between the two ports is found to be better than $-25 \mathrm{~dB}$ in the operating bands as shown in Fig 3. The experimental results are once again validated using IE3D Software. 


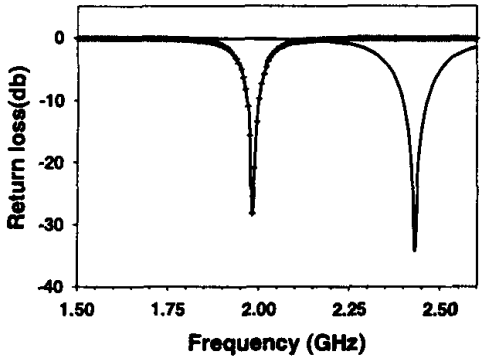

(a)

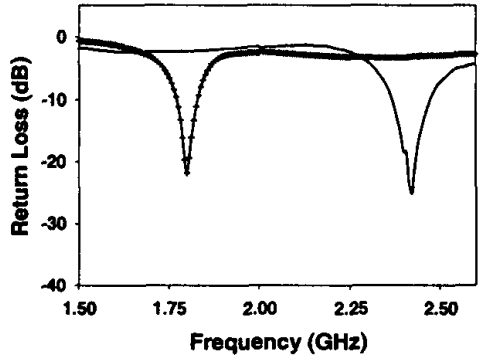

(b)

Figure.2. Variation of return loss with frequency

(a) Simulated result (b) Measured result Port 1 Port2

Radiation Patterns of the antenna at the mid-band frequency is shown in Figure.4. The radiation patterns are broad as in the case of a conventional microstrip antenna and the on axis cross polarization is better than $-20 \mathrm{~dB}$. The HPBW in the E - Plane and H - Plane is $120^{\circ}$

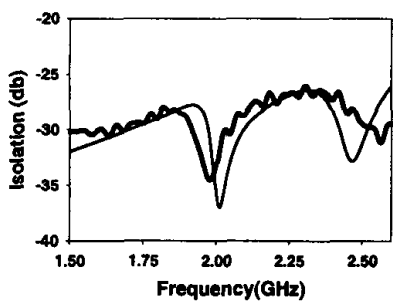
and $67.5^{\circ}$ respectively for the Port 1 radiation pattern and $90^{\circ}$ and $92.5^{\circ}$ respectively for the Port 2 radiation pattern. The table below shows a comparison of the area of the proposed octagonal patch with that of conventional microstrip antennas. An overall area reduction of $50.83 \%$ with respect to the rectangular patch area and $28.96 \%$ with respect to the circular patch area is observed.

Figure. 3.

Isolation in the operating band

- experimental result

- simulated result

\begin{tabular}{|l|l|l|}
\hline $\begin{array}{l}\text { Patch } \\
\text { Geometry }\end{array}$ & $\begin{array}{l}\text { Area at } \\
1.8 \mathrm{GHz}\end{array}$ & $\begin{array}{l}\text { Area at } \\
2.4 \mathrm{GHz}\end{array}$ \\
\hline $\begin{array}{l}\text { Rectangular } \\
\text { Patch }\end{array}$ & $21 \mathrm{Sq.cm}$ & $11 \mathrm{Sq} . \mathrm{cm}$ \\
\hline Circular Patch & $16.61 \mathrm{Sq.cm}$ & $9.235 \mathrm{Sq} . \mathrm{cm}$ \\
\hline $\begin{array}{l}\text { Octagonal } \\
\text { Patch }\end{array}$ & $11.8 \mathrm{Sqcm}$ & \\
\hline
\end{tabular}

Table.1. Comparison of area of various geometries 


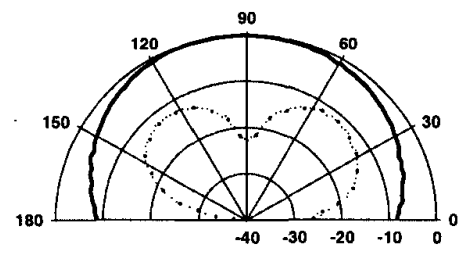

(a)

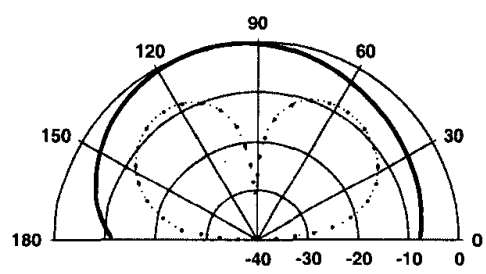

(c)

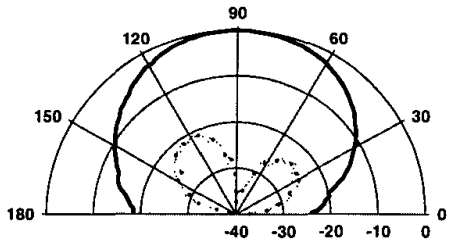

(b)

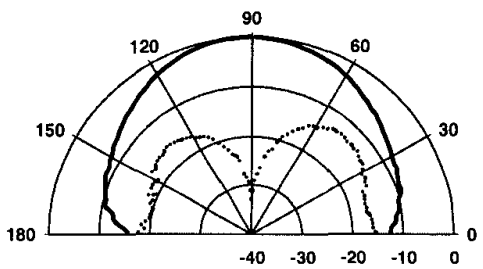

(d)

Figure.4 Radiation Pattern of ports Port 1 (a) E-Plane (b) H-Plane

Co-Polar ....Cross Polar Port2 (c)E-Plane (d) H-plane

\section{CONCLUSIONS}

A compact dual - polarized, dual band, electromagnetically coupled octagonal patch antenna has been described and investigated experimentally. The antenna exhibits dual polarized radiation characteristics. Good port decoupling ( less than $-25 \mathrm{~dB}$ ) is obtained in the entire operating band. The antenna is hence recommended for installation in mobile communication and WLAN terminals.

\section{REFERENCES}

1. S.Y.Lun, K.L.Wong, " A Dual - Frequency Microstrip - Line fed printed Slot Antenna", Microwave Opt Technol Lett 6, 2001, 373-375.

2. S.Maci and G.Biffi Gentili, "Dual frequency patch antennas", IEEE Antennas and Propagation Magazine, Vol.39, (1997), pp. 13-20.

3. Michael J. Riezenman, 'The Rebirth of Radio', IEEE Spectrum, Jan 2001, pp. $62-64$.

4. M.Deepukumar, J.George, C.K.Aanandan, P.Mohanan and K.G.Nair, "Broadband dual frequency microstrip antenna", Electron.Lett., 1996, $32,(17), p p .1531-1532$. 